\title{
Study effects of Cumin and DNA profile in diabetic Rats
}

\author{
Shayma`a J. Ahmed ${ }^{1}$, Rawah. A. Faraj ${ }^{2}$, Mahera N. Al-Shaikh ${ }^{1}$ \\ 1 Anatomy, Medicine, Baghdad University,Iraq \\ ${ }^{2}$ Community Health, Institute of Technical Medicine Foundation Of Technical Education,Iraq
}

\begin{abstract}
Recently, herbs have been used as food and for medicinal purposes and have been an exponential growth in the field of herbal medicine and these drags. Many of the oral antidibetic agents have a number of serious adverse effects, thus, managing without any side effects is still a challenge. Therefore, the search for many effective and safer hypoglycemic agents has continued to be an Important area of investigation. Besides drug classically used for the treatment of diabetes (insulin, sulphonylureas, biguanides and thazolidinediones ), several species of plants have been described in the scientific and popular literatures having a hypoglycemic activity and this activity may be due to its antioxidant properties, flavonoids are commonly found in all plants and also posses hypoglycemic and antidiabetic activities . Because of their perceived effectiveness, minimal side effects in clinical experience and relatively low cast, herbal drugs are prescribed widely even when their biological active compounds are unknown. One of these herbs is cumin which is a a pale green in color and elliptical in shape in shape with deep furrows, it is a hot, nutty flavored spice. Cumin seed was once widely used for flavoring in Europe, it is much employed in India, and it is used as a flavor in cakes and bread. Cumin is an aromatic, astringent herb that benefits the digestion and acts as stimulant to the sexual organ and improves liver function.

The aim of this research was study the biological effects of Cumin on diabetic rats and shown it is role against oxidative damage to DNA.
\end{abstract}

Key words: Cumin, damage to DNA, diabetic, DNA profile, rats.

\section{Introduction}

Fruits of Cuminum cyminum (Apiaceae), commonly known as jeera are consumed as condiment across the globe. Fruits of Cuminum cyminum (CC) are rich in estrogenic isoflavonoids luteolin and apigenin $(1,2)$ CC extract is included as one of the major components in some polyherbal formulations because of its estrogenic nature(3) and it has been reported to reduce plasma cholesterol levels in diabetic rats(4).

Diabetes mellitus a complex syndrome is characterized primarily by the imbalance in blood glucose homeostasis leading to hyperglycemia and series of secondary complications caused by an absolute or relative lack of insulin. In conventional theory, type I diabetes is treated with exogenous insulin and type II with oral hypoglycemic agents ( 5).

Many of the oral antidibetic agents have a number of serious adverse effects, thus, managing without any side effects is still a challenge. Therefore, the search for many effective and safer hypoglycemic agents has continued to be an Important area of investigation. Besides drug classically used for the treatment of diabetes ( insulin, sulphonylureas, biguanides and thazolidinediones ), several species of plants have been described in the scientific and popular literatures having a hypoglycemic activity and this activity may be due to its antioxidant properties (6), flavonoids are commonly found in all plants and also posses hypoglycemic and antidiabetic activities ( 7).

Bitter cumin is used extensively in traditional medicine to treat a range of diseases from vitiligo to hyperglycemia. It is considered to be antiparasitic and antimicrobial and science has backed up claims of its use to reduce fever or as a painkiller. New research published in BioMedCentral's open access journal BMC Complementary and Alternative Medicine shows that this humble spice also contains high levels of antioxidants, in other hand the reactive oxygen species (ROS) also known as free radicals, are produced as part of the metabolic processes necessary for life. Oxidative stress, however, is caused by overproduction or under-removal of these free radicals. Oxidative stress is itself involved in a number of disorders, including atherosclerosis, neural degenerative disease, inflammation, cancer and ageing. Antioxidants are thought to mop up these free radicals, reduce oxidative stress, and prevent disease(8).

\subsection{Animals experiments}

\section{Materials and Methods}

Twenty five adult of rats were used in this study, and isolated in a relatively controlled environment at temperature of about $25^{\circ} \mathrm{C}$ in the "Animal breeding center-college of Medicine-Baghdad University". They were given food and free access to water. 
Diabetes was induced by a single dose of $100 \mathrm{mg} / \mathrm{kg}$ (body weight) intraperitoneally injection of alloxan monohydrate( BDH chemicals Ltd ,England, product no. 4201) dissolved in D.W. immediately before use and infused over a period of 10 min. to overnight fasted animals (9), because glucose is known to protect the beta cell and prevent the superoxide derivative, which cause the cell damage (10) the rats were kept for the next $24 \mathrm{hr}$. on 5\% glucose solution bottles in their cage to prevent hypoglycemia (11). After fortnight rats with moderate diabetes having hypoglycemia with blood glucose range of $250-300 \mathrm{mg} / \mathrm{dl}$, were used for this study . 5 days after alloxan injection (to make sure that diabetes was induced), diabetic animals were treated with cumin. Rats were fasted for 12 hours prior to sacrificing, animals anesthetized by using Nembutal solution $(0.06$ ml/gm body weight) (S.SN. A. LaBallasler, 33501 Libourne cedex France), blood samples were collected for biochemical study. The samples were liver presented in $10 \%$ of formalin for genetic study.

The rats were divided into five groups each group was consist of (5mice):

1-First group: was treated with (5\%) cumin for (14) days.

2-Second group: was diabetic and treated (5\%) cumin for (14) days.

3-Thrid group: was diabetic and treated (5\%) cumin for (7) days.

4-Forth group: was diabetic.

5-Fifth group: was normal.

\subsection{Biochemical tests}

Blood glucose levels were measured with enzymatic oxidation(12) . serum lipid and serum triglycerides levels were measured according to Teaching Laboratories -Medical city of Baghdad.

\subsection{DNA extraction}

DNA was extracted from liver of six groups according to (Bioneer- Korea) by using Ultra violated spectrophotometer (CECIL, CE 7200) the DNA concentration was measured, finally the DNA was electrophoresed by using (1\%) agrose gel electrophoresis at $(3 \mathrm{~V} / \mathrm{cm})$ for $(90 \mathrm{~min})$ (13).

\subsection{Statistical analysis}

Changes in glucose, serum lipid and serum triglycerides in blood of Rats were compared statistically by means of one way analysis of variance (ANOVA) test. P-value less than 0.05 considered to be significant.

\section{Results}

Changes in glucose, serum lipid and serum triglycerides in blood of rats are summarized in the table 1.The DNA electrophoresis results are demonstrated in Fig. 1

Table-1- Changes in glucose, serum lipid and serum triglycerides in blood of Rats.

\begin{tabular}{|l|l|l|l|}
\hline samples & $\begin{array}{l}\text { Glucose } \\
(\mathrm{mg} / \mathrm{dI})\end{array}$ & $\begin{array}{l}\text { Total serum lipid } \\
(\mathrm{mg} / \mathrm{dI})\end{array}$ & $\begin{array}{l}\text { Serum triglycerides } \\
(\mathrm{mg} / \mathrm{dI})\end{array}$ \\
\hline Normal control & $85 \pm 1.6$ & $98.5 \pm 2.1$ & $97.5 \pm 2.5$ \\
\hline Diabetic & $300 \pm 3.5$ & $140 \pm 3.2$ & $154 \pm 6.2$ \\
\hline (5\%) cumin for (14) days & $90 \pm 1.5$ & $110.6 \pm 5.2$ & $114 \pm 5.4$ \\
\hline $\begin{array}{l}\text { Diabetic\& treated (5\%) cumin for } \\
(14) \text { days }\end{array}$ & $160 \pm 2.0$ & $112.7 \pm 3.3$ & $11.5 \pm 3.2$ \\
\hline $\begin{array}{l}\text { Diabetic\& treated (5\%) cumin for } \\
\text { (7) days }\end{array}$ & $150 \pm 1.8$ & $114 \pm 3.2$ & $113 \pm 2.4$ \\
\hline
\end{tabular}

Values are mean \pm SEM

$\mathrm{P}<0.05$

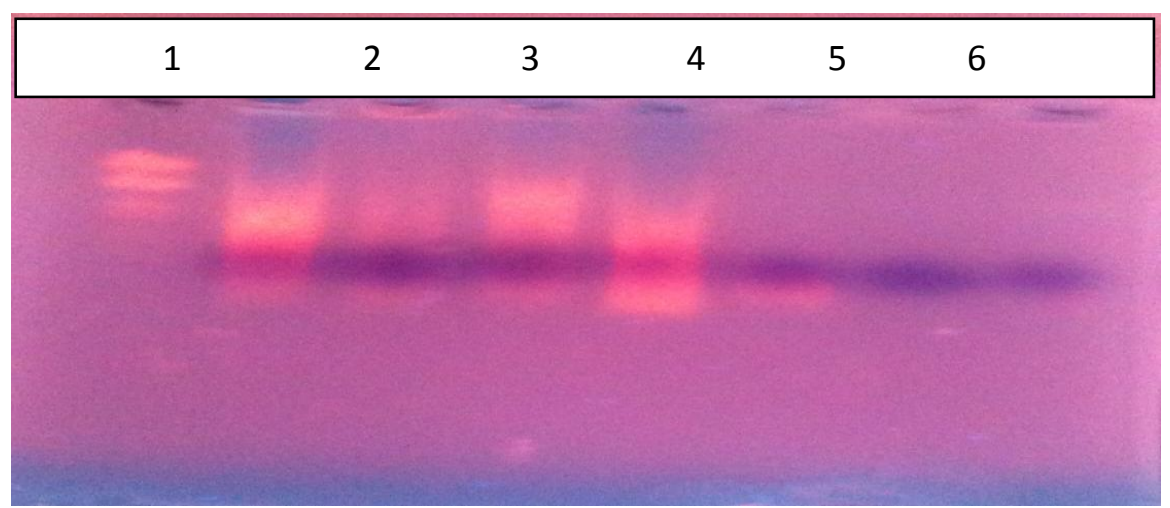

Fig. 1 DNA electrophoresis. 
Lane-1- Lamdba DNA ,Lane-2- Normal control , Lane-3- Diabetic , Lane -4- (5\%) cumin for (14) days, Lane5- Diabetic\& treated (5\%) cumin for (14) days, Lane-6- Diabetic\& treated (5\%) cumin for (7) days. DNA was electrophoresed by using (1\%) agrose gel electrophoresis at $(3 \mathrm{~V} / \mathrm{cm})$ for $(90 \mathrm{~min})$.

\section{Discussion}

Herbs have been used as food and for medicine purposes for centuries. In the last few years there has been an exponential growth in the field of herbal medicine and these drugs are gaining popularity both in developing and developing countries because of their natural origin and less side effects as the researches has been provided.

Many traditional medicines in use are derived from medicinal plants, minerals and organic matter. The use of medicinal herbs has focused on various herbs that posses anti-platelets, anti-tumor or immune stimulating properties that may be useful adjunct in reducing the risk of disease and treatments(14).

In this study Twenty five rats were divided into five groups, the first group was normal control, and the second group was Diabetic. The third group was (5\%) cumin for (14) days. The four group was Diabetic\& treated (5\%) cumin for (14) days, and the five group was Diabetic\& treated (5\%) cumin for (7) days.

Table 1, indicated that there was significantly differences in the levels of Blood glucose, serum lipid and serum triglycerides in both Diabetic\& treated (5\%) cumin for (14) days group and Diabetic\& treated (5\%) cumin for (7) days as compared to control animals, Diabetic, and (5\%) cumin for (14) days. This results are in agreement with Al-Shaikh et.al. results(14).

From the DNA electrophoresis (Fig. 1) it can be seen that the (5\%) cumin for (14) days, and Diabetic\& treated $(5 \%)$ cumin for (14) days give a band with smear of DNA extraction, but only Diabetic and also Diabetic\& treated $(5 \%)$ cumin for (7) days give smear. This mean that the damage to DNA is occurred and treatment with $(5 \%)$ cumin take more than (14) days.

As conclusion cumin can be recommended as a dietary protect diabetic damage to DNA, also can be recommended as a support for the prevention of diabetic complications.

\section{References}

[1] S.S.Shirke \& P. Jagtap.Effects of methanolic extract of Cuminum cyminum on total serum cholesterol in ovariectomized rats. Indian J.Pharmcol. 41(2), 2009 ,92-93.

[2] Dr.Dukes, Phytochemical and ethnobotanical databases. Available from: http://www.drdukes.com/. [last accessed on 2005 Jan 24]

[3] T. Malini \& G. Vanithakumari, Estrogenic activity of Cuminum cyminum in rats. Indian J Exp Biol., 25, 1987,442-4.

[4] S.Dhandapani , VR.Subramanian, S. Rajgopal \& Namasivayam N., Hipolipedemic effect of Cuminum cyminum L. on alloxan induced diabetic rats. Pharmacol Res.,46,2002,251-5.

[5] C. Rosak, When diet and oral antidiabetics are no longer enough. Optimal management of the diabetic patient with insulin MMW Fortschr Med., 144, 2002 ,28-34.

[6] J. R. Colca, Insulin sensitizers may present metabolic inflammation. Biochem.Pharmacol.,72, 2006,125-131.

[7] B.Sharna, G. Viswanath \& R. Salunke, Effect of flavonoid - rich extract from seeds of Euggenia gambolana ( L .) on carbohydrate and lipid metabolism in diabetic mice . Food Chem., 110, 2008 , 697-705.

[8] V. Ani, \& K. A. Naidu, Bitter cumin contains high levels of antioxidants and protects against DNA damage News Medical . October 2, 2012

[9] T.Ohno, j.Kitoh, K. Yamashita, Y. Ichikawa \& F. Horio, Toxin - induced IDDM ( insulin dependent diabetes mellituse ) in the musk shrew, Life-Sci . 63 (6), $1998,455-62$.

[10] G. A. Y. Martens, S. Cai, , G. Hinke, M. V. Stange \& C. Pipeleers, Glucose suppresses superoxide generation in metabolically responsive pancreatic $\beta$-cells . J . Biol . Chem. ,280, 2005,20389-20396.

[11] P. S. M. Prince, V. P. Menon \& L . Pari, Hyperglycemic activity of Syzigium cumini seeds : effect on lipid peroxidation in alloxan diabetic rats . J.Ethnopharmacol ., 61, 1998, 1-7.

[12] K.D. Pagana\& T.J. Pagana, Mosby’s Manual of Diagnostic and Laboratory Tests, 2006, 3rd edition.

[13] J. Sambrook, E. F. Fritsoh \& T. Maniatis, Molecular cloning: A laboratory manual. $2^{\text {nd }}$ edition.1989.

[14] M.N. Al-Shaikh, N.K. Yas \& H.H. Hamdu, The effects of wild cherry \& cumin on erythromycin-induced hepatic inflammation in diabetic rats. Biochemical, histological \& histochemical study. Fac. Med. Baghdad, 53(4), 2011, 461-466. 